\title{
The Commercialization of Beijing Hutongs
}

\author{
Ruoxuan $\mathrm{Mao}^{1}$ \\ ${ }^{1}$ Beijing National Day School, Beijing, China \\ Correspondence: Ruoxuan Mao, Beijing National Day School, Beijing, No. 66, Yuquan Road, China. Tel: 86-182- \\ 1035-1519. E-mail: 2038703659@qq.com
}

Received: August 3, 2018

doi:10.5539/jgg.v10n4p39

\author{
Accepted: September 10, $2018 \quad$ Online Published: November 27, 2018 \\ URL: http://dx.doi.org/10.5539/jgg.v10n4p39
}

\begin{abstract}
This paper addresses the transition of Hutongs from alleys connecting the main streets to fully commercialized districts. Hutongs are narrow streets formed by rows of Siheyuans (quadrangle dwellings), a traditional type of Chinese architecture consists of four houses surrounding a courtyard. The architectural layout of Siheyuan is four houses surrounding a courtyard. There are several types of Siheyuans, including the Beijing Siheyuan. Along with the development of Beijing since 1949, numerous Siheyuans were demolished. However, since the 1980s, many Hutongs were brought under national and local protection. Some of the best preserved Hutongs, especially those in the center areas of Beijing, are now more commercialized than they were prior to the ' $80 \mathrm{~s}$. This paper discusses the causes as well as consequences of such commercialization. Literature concerning the Hutongs frequently discusses the Hutongs' history and the shift in their architectural design, as well as other aspects that have changed over time. By contrast, this paper discusses a special phenomenon of Hutongs in Beijing - commercialization and focuses on the causes and results of it.
\end{abstract}

Keywords: Beijing Hutongs, Siheyuans, commercialization, preservation, government policies

\section{Introduction}

With more than 740 years of history, Nanluoguxiang (in Chinese: 南锣鼓巷), is a typical example of a commercialized Hutong. Conservation districts with historic sites, such as Nanluoguxiang, have attracted a large number of visitors. In 2016, Nanluoguxiang attracted more than 30,000 visitors daily, while the number of visitors at any one time was 17,000 people, which exceeded what the site could handle. The site-according to the Beijing Tourism Commission - was disqualified from classification as a "National AAA level" scenery spot because of its traffic (there are five quality levels of tourist attractions; the "AAA" level is the third level). In response, Nanluoguxiang stopped receiving tour groups so as to control the number of visitors. Nanluoguxiang's popularity is largely related to its commercialization.

The commercialization of such Hutongs is a result of multiple factors, which will be discussed in the following pages. Before a discussion of these different factors, a brief overview of the government policies concerning the preservation and commercialization of certain Hutongs, as well as the change in form and number of Hutongs, is necessary.

\section{The History and Government Policies of Beijing Hutongs}

\subsection{The History of Beijing Hutongs}

In the centuries before 1949, the number of Beijing Hutongs generally trended upwards: from 413 during the Yuan Dynasty (1271 A.D.-1368 A.D.), to 1170 during the Ming Dynasty (1368 A.D.-1644 A.D.), and to 2077 during the Qianlong period of Qing Dynasty (1736 A.D.-1795 A.D.). Research done by Surveying and Mapping Institute of Beijing (cited in Beijing Hutong 2008), however, indicates the more recent decline of the number of Hutongs from 1949 to 2003. In 1949 there were 3073 Hutongs; in 1965 there were 2,382; in 1980, 2,290; in 1990, 2,242. Finally, by 2003 , there were only 1,559 Hutongs in Beijing. Not only has the number of Hutongs changed overtime, but also their forms and names. Huiqi Zhang wrote in Beijing Hutong that with the development of cities of the past dynasties, the width and direction of some old Hutongs changed.

The names of some Hutongs were also changed by the government and local civilians. Many Hutongs were at first named after their functions or design characteristics. For instance, Hutong names like Erduoyan ("ear hole"), Yuyan ("fish eye"), and Zhenbier ("the eye of a needle") reflected that these alleys were short, whereas names like 
Zaner ("hairpin") and Zhuyiba ("pigtail") indicated that these two Hutongs were narrow and long. The Bingjiaokou Hutong ("Bingiiao" means icehouse in Chinese) was named after the icehouse located in the Hutong during the Qing Dynasty. Since the onset of the Republic of China, the government has replaced many "inappropriate" names with more "appropriate" ones, such as changing Zhuyiba Hutong to Zhuweibo Hutong (the renaming process usually involves the use of homophones), out of the concern that the previous names were too "vulgar." Sometimes the names of some Hutongs changed with their function. Among all the changes that occurred, the decrease in the number of Hutongs is one of the most predominant factors that resulted in their commercialization, which I will detail later in this paper.

The preservation of historical buildings, including Siheyuan, has long been a pressing issue. In 1950, Sicheng Liang and Zhanxiang Chen - experts in architecture and urban planning - proposed, in "Suggestions on the Location of the Administrative Center of the Central People's Government," the preservation of the old city of Beijing, which would then serve as a "city museum." In the meantime, a new city - the political center of Beijing, in the city's western suburb - would be formed. The old and new cities would be connected by a main road. The map (figure 1) on the next page shows the old city and the political center divided by the city walls (the old one on the right side and the new one on the left side). Figure 2 is a sketch of a city wall garden, proposed by Sicheng Liang during the Beijing urban construction conference in 1951, which planned to preserve all the city walls and gates. The sketch depicts the relationship of people to the gardens. However, due to interest in recovering and developing industry and the economy after World War II and the Civil War, the proposal was abandoned. The old city walls and most of the gates were demolished. Hutongs faced the same problem. Following 1949, many Hutongs were demolished for the purpose of developing the city and its means of transportation. As previously mentioned, the number of Hutongs fell from 3,073 in 1949 to 1,559 in 2003.

Although many people doubt the feasibility of the proposal presented by Liang and Chen, its idea of preserving ancient architecture and culture can be applied to the commercialization method in the last section of this paper.

The public as well as government realized the value of historic architecture in the 1980s and 1990s. The reasons for this shift are complicated to discern. One reason could be the reform policies (in Chinese: 改革开放) implemented since 1978, which marked the start of multiple reforms concerning aspects of life such as education, the economy, and housing. It is possible that these policies promoted people to have a better sense of "preservation" (Note 1). Another reason could be that the residents of many Hutongs were forced to leave their homes, which had been the property of their ancestors and move to apartments due to the development of urban road and traffic system. This may also have increased public attention for Hutong preservation.

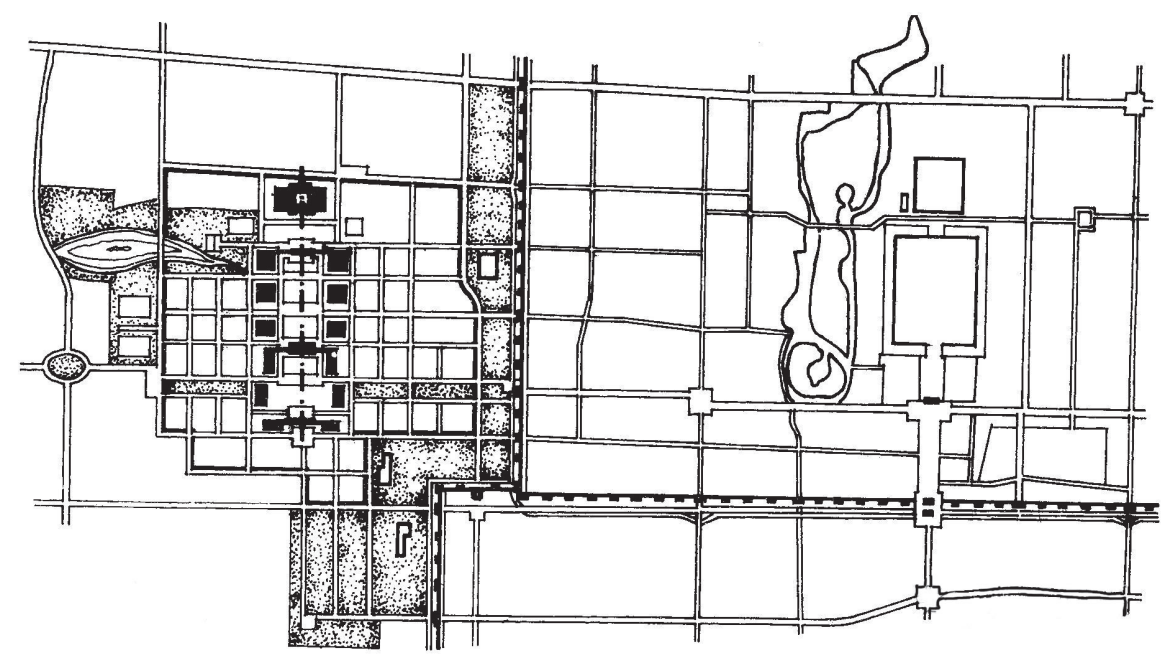

Figure 1. Map of New City and Old City in the Liang-Chen Proposal 


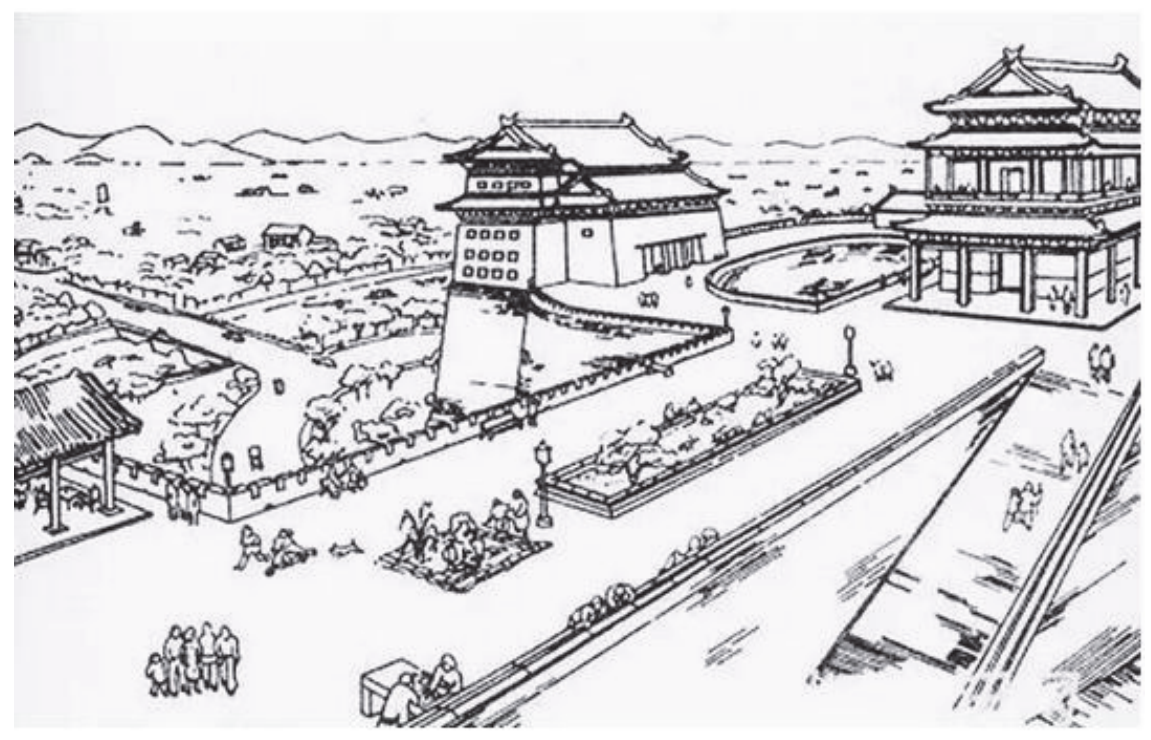

Figure 2. City Wall Garden

\subsection{Government Policies concerning Hutongs}

The city plan in 1999, formulated by the Beijing urban and rural planning commission and approved by the Beijing Planning and Construction Committee, designated 25 conservation districts for historic sites (14 in the Imperial City, seven in the inner city and four in the outer city). These 25 sites were determined to be well-preserved, and to possess high cultural and historical value. Furthermore, under this plan, the districts along the north-south axis of Beijing, such as the Imperial City, the three rear lakes, the Bell and Drum tower, Qianmen-Dashilan, the Temple of Heaven, and the Temple of Agriculture, would be linked together, forming "the core protection area of the historic and cultural essence of the old city."

Although the government recognized the value of Hutongs, many Hutongs were deemed eligible for demolition, which reduced their number more rapidly. 683 Hutongs were demolished from 1990 to 2003, which signified a large decrease in the number of Hutongs, compared to 48 from 1980 to 1990. The Beijing Municipal Government released document in 2002 regarding plans to demolish or reconstruct houses in bad condition. According to the documents, the restructuring project aimed at housing reform in Beijing, especially in the old city, and this engendered the demolition of many Siheyuans that were consider to be dangerous or outdated as housing complexes. Thus, the number of Hutongs declined. At the same time, the government also released documents regarding the development of new Hutongs.

In 2012, the Beijing municipal government published and distributed documents that established plans for the further development of tourism. They expressed that tourism could catalyze the development of more than 110 related industries. Regarding the "core function area of the capital" in which there were many historic sites, the government planned to integrate touristic elements - including restaurants, accommodations, transport, entertainment, travel services, and shopping stores — to form a touristic complex. For the ShichahaiNanluoguxiang district, the government proposed to showcase Siheyuan culture, introducing and establishing existing business enterprises, as well as developing touristic service sites in Siheyuans.

\section{The Causes and Consequences of the Hutongs' Commercialization}

\subsection{The Causes of Hutongs' Commercialization}

The commercialization of certain Hutongs, including Nanluoguxiang, was a result of the demolition as well as the preservation of Hutongs. Moreover, the actions of Siheyuan owners, shop owners, and the government's plan to promote tourism have all had a positive influence on the commercialization.

Between the 1980s and 1990s, there was a shift in public perception about the preservation of Hutongs. Since then, many Hutongs have been designated and protected by the government. Although the preservation and destruction process might occur simultaneously (731 Hutongs were demolished from 1980 to 2003), people's general opinion had changed in terms of thinking about the Hutongs as historic sites that needed to be preserved, rather than barriers to city development. For example, government plans for Hutong preservation were released in the 1990s and 2000s, 
leading to the appearance of some historic protections. Another proof of this transition is that during this period of time more and more tourists began to visit historic sites including the Hutongs, which shows that people recognized the value of these sites. From then on, citizens and the government acknowledged the Hutongs' historical and cultural value.

The commercialized Hutongs, interestingly, are mostly those being designated by the Beijing Urban and Rural Planning Commission in the city plan published in 1999 (which selected 25 conservation districts). This is because, although all Hutongs may have historical and cultural value, these Hutongs were deemed especially valuable by the government (as explained in the previous section concerning government policies). In order to be commercialized, a Hutong must have commercial value. The historical and cultural value of Hutongs are, however, part of that. Apart from Hutongs' historical and cultural value, the decrease in the number of Hutongs also has been a factor that had made them commercially valuable: due to the fact that many Hutongs were demolished after 1949 , they are becoming rarer and rarer, resulting in an increase in their value.

The commercialization process of certain Hutongs was the effort of tourists, local residents (oftentimes Siheyuan owners) of commercialized Hutongs, shop owners, and the government. Initially, tourists visiting these Hutongs - no matter if they were attracted to the history of the buildings or merely by the shopping — incentivized more shops to enter these Hutongs and thus promote the commercialization process. Additionally, Hutongs attracted a large number of visitors after being protected as historic sites and the rent of Siheyuans became higher when more and more stores were attempting to be part of the tourism complex. Therefore, The Siheyuan owners, especially those who inherited Siheyuans from their relatives and were unable to adjust to the new facilities in Siheyuans (Note 2), were willing to rent out their houses. Finally, the government also played a crucial role in the commercialization. Apart from the 1999 preservation plan, the government further promoted commercialization by developing tourism. For instance, in 2012, the Beijing municipal government promoted the commercialization of designated Hutongs (namely, the Qianmen-Dashalan and Shichahai-Nanluoguxiang districts) through establishing touristic complexes and introducing old business enterprises, which further increased the number of shops in these Hutongs. In Nanluoguxiang, for instance, government policy and tourism led to the opening of liquor stores, general retail shops, jewelry shops, crafts shops, snack bars, restaurants, cafes, barbershops, travel agencies, clothing shops, hotels, and more (Note 3). The diversity of commercial enterprises satisfied the various needs of visitors. Siheyuan owners, shop owners, and the government, all promoted the Hutongs' commercialization.

\subsection{The consequences of Hutongs' Commercialization}

The commercialization of the Hutongs had many consequences, and some had not been anticipated by the government and the public at first. By renting out Siheyuans, selling products or providing services, the Siheyuan owners and store owners benefited from the Hutongs' commercialization. The government, through promoting tourism, was able to achieve the goal of raising GDP and revenue.

However, beyond these economic benefits, commercialization has resulted in additional effects. One is that the commercialization caused damages to the Siheyuans. In the case of Nanluoguxiang, the Dongcheng District municipal government published and distributed documents concerning the protection of historic sites, setting up detailed rules. Such behaviors of damaging Siheyuans still exist and, indeed, are inevitable when there is such a large number of tourists and stores in Hutongs.

Commercialization, furthermore, can destroy the Hutong-Siheyuan living pattern. Such living patterns can be protected when the local residents live in Siheyuans as they are considered part of the Hutong culture. Nevertheless, as more and more residents rent out their house or move to other buildings, the Hutong-Siheyuan living pattern may vanish.

\section{The Strategy and Level of Commercialization}

The strategy and the level of commercialization are correlated to these consequences. If the level or the strategy is excessive, for example, if a Hutong is over commercialized, then both the local living pattern and architecture could be damaged. There is no doubt that there will be damage to the historical and cultural value of Hutongs if this happens. In other words, "inappropriate commercialization" can influence Hutongs in a negative way and decrease their commercial value. But if the level or the strategy is appropriate, the commercialization not only brings economic benefits, but also avoids destroying architecture and local culture. The question is, what level of the commercialization can be considered "appropriate"?

\subsection{Cases Analysis}

Take the districts of Nanluoguxiang and Dashilan as examples. 


\subsubsection{The Condition of Nanluoguxiang}

The map (figure 3) shows the Hutongs in the Nanluoguxiang area, which includes 17 Hutongs, with the Nanluoguxiang Hutong in the middle. The remaining 16 are perpendicular to the Nanluoguxiang Hutong, 8 in the West and 8 in the East, forming the shape of a centipede. The 8 Hutongs in the West are named Qiangulouyuan, Heizhima, Shajing, Jingyang, Mao'er, Yu'er, and Suoyi. The 8 Hutongs in the East are Ju'er, Houyuanensi, Qianyuanensi, Qinlao, Beibingmasi, Dongmianhua, Banchang and Chaodou Hutong.

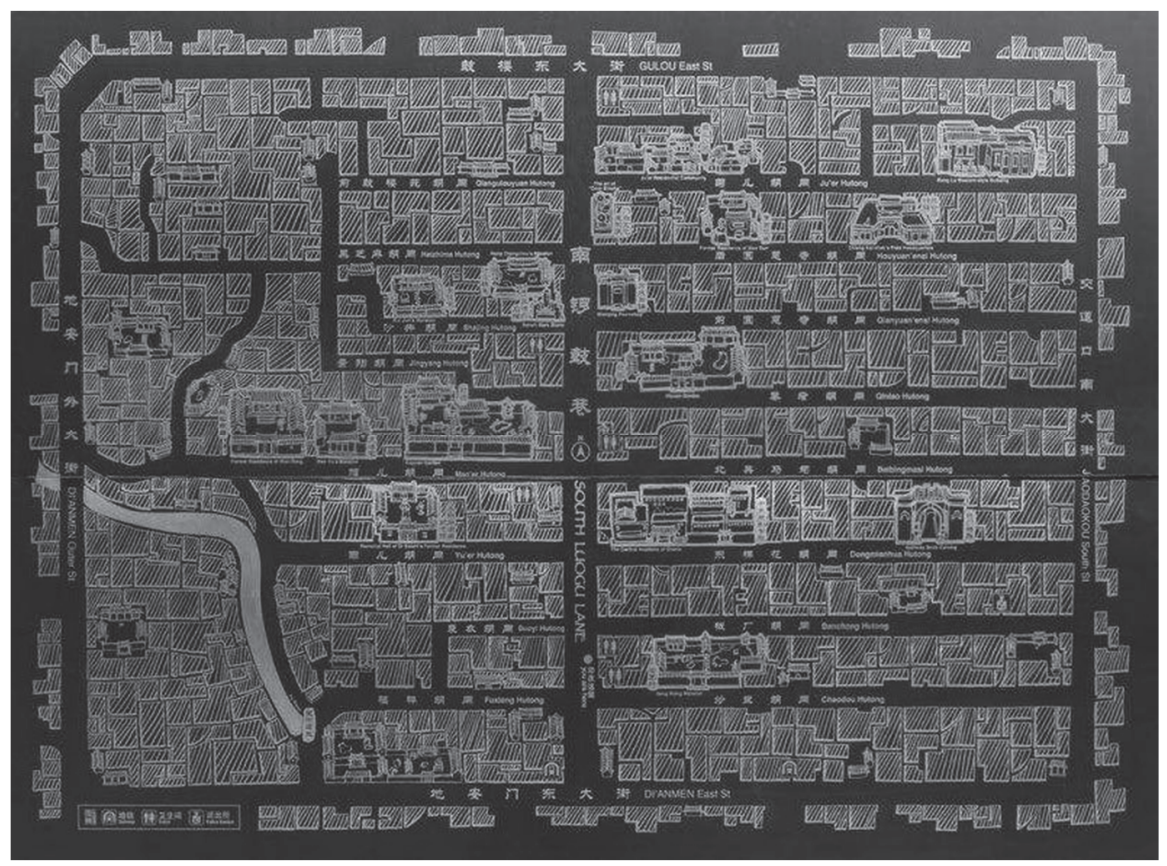

Figure 3. Map of Nanluoguxiang area (photo by the author)

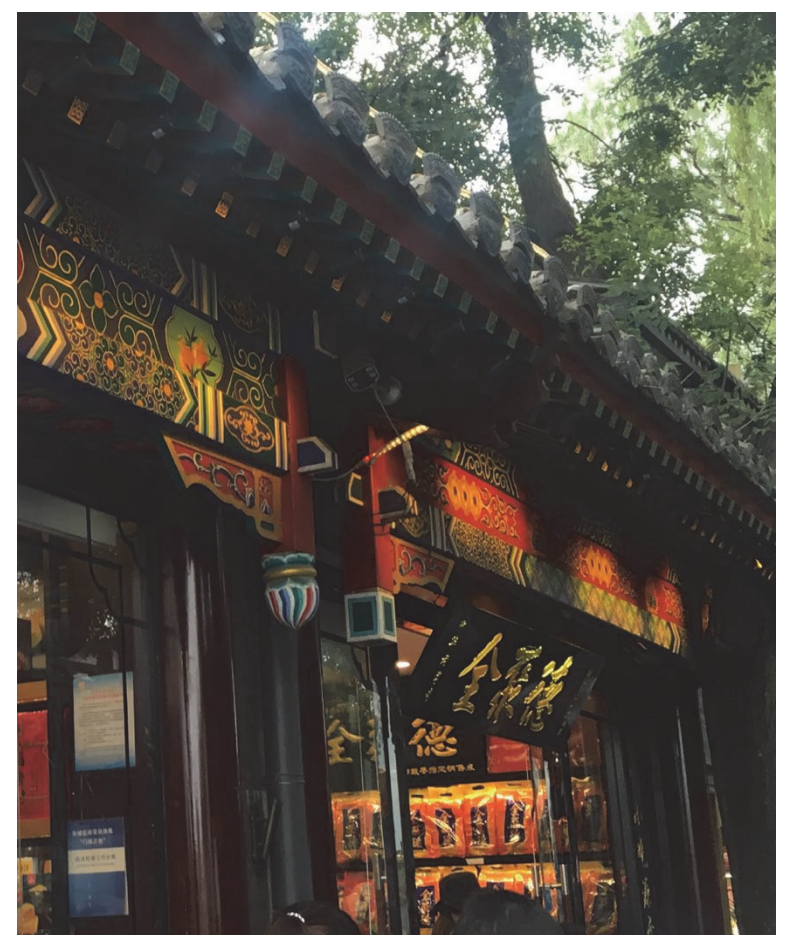

Figure 4. Picture of Quanjude

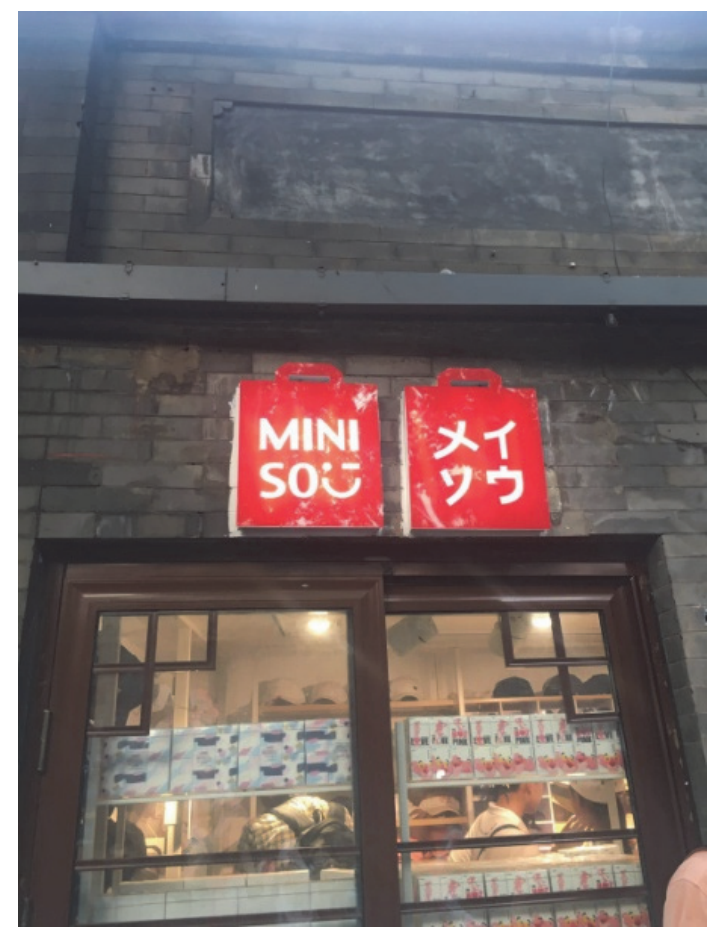

Figure 5. Picture of a shop, NIMISO

(Photos by the author) 
One characteristic of the Nanluoguxiang area is that most shops concentrate in the Nanluoguxiang Hutong, while other Hutongs generally maintain their original function, architectural features, and spatial layout.

The picture in Figure 4 shows Quanjude, a restaurant chain especially famous for its Beijing Roast Duck). It is considered a "Lao Zihao," or time-honored brand in Beijing. The presence of stores like these in the area could be the fruit of the 2012 government plan to introduce and reopen old business enterprises. Figure 5 depicts a general store MINISO; the brand was registered in 2016, which means that it is relatively new. Stores in Nanluoguxiang include shops both with local characteristics and without such characteristics, such as: Japanese restaurants, general shops like MINISO, as well as famous brands that are not related to local culture but attract visitors. This is an indication of an interest in commercial development.

The number of commercial tenants in Nanluoguxiang has increased in recent years, which could be estimated through the taxpayer data. According to the Beijing Municipal Tax Service, State Administration of Taxation, the number of taxpayers grew from 67 to 97 between 2015 and 2017, while in 2017 the total local tax payment was 440.000 yuan (approximately USD \$63,584) and the total national tax payment was 1.146 .900 yuan (approximately USD \$165.737). Although the government took measures to disperse non-capital functions which resulted in to shut down of numerous shops and factories in Beijing (Note 4), the number of taxpayers has continued to increase. A of July 26, 2018, there were 161. Thus, we can see that Nanluoguxiang is a highly commercialized Hutong and would achieve a higher level of commercialization due to the growing number of commercial tenants.

To evaluate whether the commercialization level is appropriate, we must think about two important factors: first, whether there are preexisting shops or services in the Hutongs that can attract large numbers of tourists; and, second, whether the existence of these shops and services destroys architecture (in this case, the Siheyuans) or the Hutong-Siheyuan mode of living. In other words, we need to consider whether or not the commercial value of these Hutongs will dissipate after the commercialization.

Let's start by focusing on the first aspect: whether there are shops and services that attract visitors. The answer is yes. Almost every commercialized Hutong attracts a considerable number of visitors. Nanluoguxiang, as previously mentioned, had more than 30,000 visitors per day in 2016.

Thus, we should ask the second question: does commercialization imperil Hutong-Siheyuan living patterns, or even Siheyuans themselves? Indeed, this is also a crucial factor that attracts visitors.

The Nanluoguxiang district, apart from Nanluoguxiang Hutong itself, is a relatively well-preserved area. Figure 6 shows a Hutong that connects the Nanluoguxiang Hutong together. The original functions of Siheyuans in this area are generally maintained - most of them serve as residences, other serve as restaurants and shops. Figure 7 shows the gate of a Siheyuan in the Suoyi Hutong. The sign on the gate "No visitor allowed, staff only" — and, in Chinese, "私人住宅, 请勿入内" — indicates that the house still serves as a residence, and thus the Hutong-Siheyuan living pattern is maintained.

The 16 Hutongs in the Nanluoguxiang area are not excluded from commercialization. There are restaurant and shops in these Hutongs, too, but far fewer than those in Nanluoguxiang. Thus, the 16 Hutongs' living patterns and culture are kept in general as most of the Siheyuans' function are maintained and the residents still live in these courtyard houses.

The condition of Nanluoguxiang area is that the Nanluoguxiang Hutong is highly commercialized, but the other nearby are less commercialized (although some tourists also visit these places). The Hutong-Siheyuan living patterns have been almost totally destroyed as Hutongs and Siheyuans have shifted from residential areas to touristic sites. In the Nanluoguxiang Hutong itself, most Siheyuans now serve as shops and restaurants. Nonetheless, the rest of the Nanluoguxiang area maintains its traditional living pattern. Moreover, the Siheyuans in the Nanluoguxiang area are mostly well-preserved and their original spatial structure remains. The area has a relatively appropriate commercialization level compared to most of the commercialized Hutongs in Beijing because the buildings retain most of their original functions (except for the Nanluoguxiang Hutong), the local living pattern art mostly kept in the 16 remaining Hutongs and the Siheyuans are preserved. However, the Nanluoguxiang Hutong does not satisfy the description outlined above and the commercialization has a negative effect on the local culture and living pattern. 


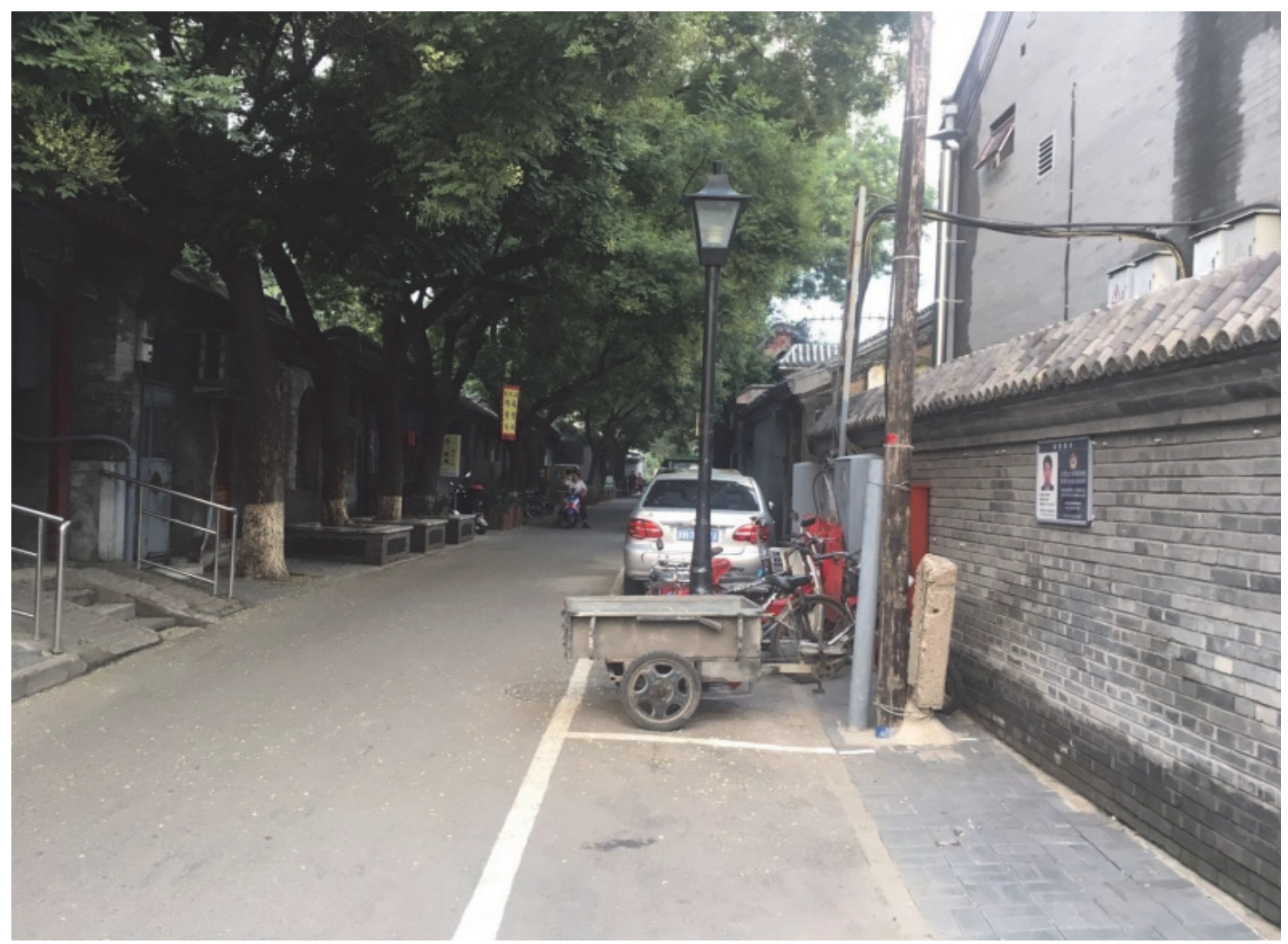

Figure 6. Picture of a Hutong in the Nanluoguxiang area (photo by the author)
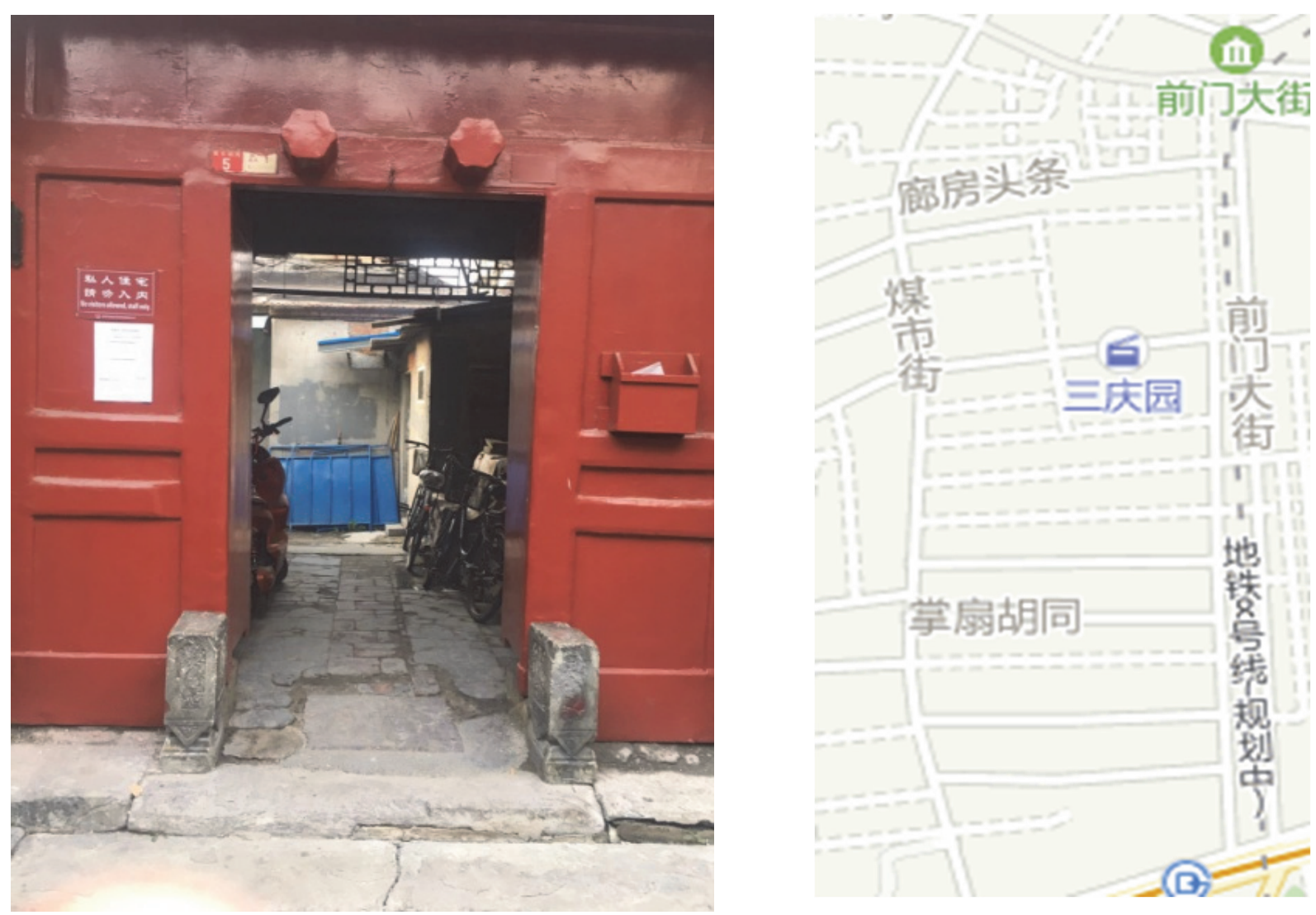

Figure 7. the gate of a Siheyuan

Figure 8. the map of Dashilan area 
(photo by the author)

(picture from the Sougo Map)

\subsubsection{The Condition of Dashilan}

A second example is Dashilan district, an area formed by three north-south streets: Meishi Street, Liangshidian Street, and Zhubaoshi Street. There are nine east-west Hutongs (figure 8). The center of the Dashilan area is the Dashilan commercial street (Note 5).

The functions of these Hutongs and streets are mostly retained. The Dashilan has been a commercial center since Qing Dynasty and there are now a large number of Lao Zihao, while some of the surrounding Hutongs have become more commercialized, there is still has a low level of commercialization.

In 2007, the government of the Xuanwu District (present-day Xicheng District) released documents regarding plans for the next five years. They revealed a plan to demolish illegal buildings and to overhaul 47 Hutongs in the district in preparation for the 2008 Olympics. The government initiated the Dashilan renovation project in May 2007, resulting in the renovation of many buildings in Dashilan and the widening of the main commercial street. However, the shortcomings of the project were significant. Although several Hutongs still maintained their form, the commercial street, the central part of the Dashilan district, was largely harmed. Today, most architecture consists of contemporary buildings designed to look like ancient ones (as seen in Figure 9). Although this renovation project successfully attracts visitors, Dashilan has lost much of its historical and cultural value as much of the ancient architecture has been lost and were replaced by contemporary ones that mock the architectural style of the old ones.

Again, to assess the level of commercialization, it is necessary for us to consider two factors. First, Dashilan attracts an average of 150,000-160,000 visitors daily. Indeed, high visitation contributes to Dahilan's commercial value. As for the second factor, the functions and local living pattern of the Dashilan area are successfully maintained, but most buildings in its central area have been destroyed, which reduces its historical and cultural value and decreases its commercial value. Due to the negative effects, particularly to serve architectural damage, we can determine that the amount of commercialization in the area, as well as the strategy with which it was carried out, is inappropriate.

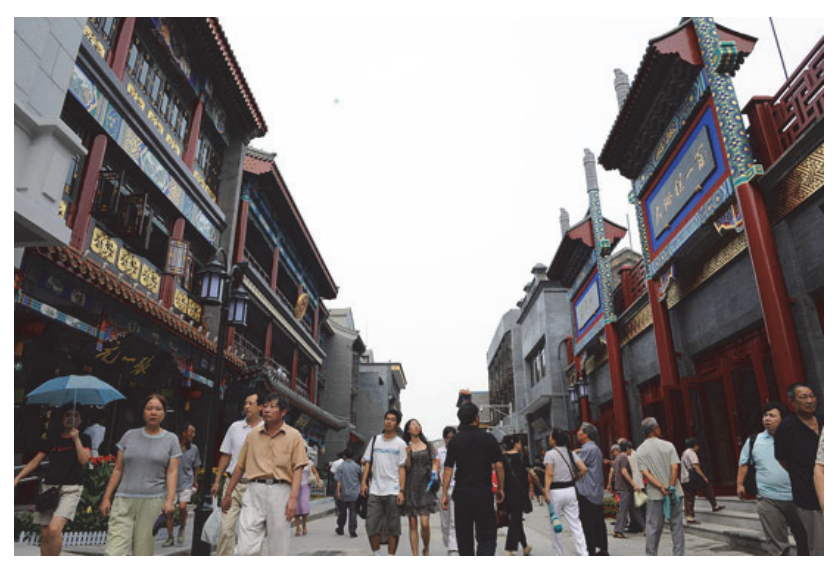

Figure 9. Picture of the contemporary buildings in the Dashilan Commercial Street

(Photo by the Xinhua News Agency)

All in all, the commercialization of in neither Nanluoguxiang or Dashilan has tourist-driven commercialization been achievable without harming local culture and architecture. However, the conditions of Nanluoguxiang are better than those of Dashilan because the architecture and its spatial layout are not changed or destroyed. That said, the next section of this paper explores a potential solution to these issues - a new method that could, possibly, help us define an "appropriate" level of commercialization.

\subsection{A Solution to Avoid the Negative Consequences of Commercialization}

The two cases discussed in the previous section reveal how difficult it is it is for a successful commercialized Hutong to attract visitors while maintaining its culture (or tradition) and architecture.

One possible solution for retaining local culture is to encourage locals to run their own businesses. In fact, this 
commercial mode is already existent in many historic sites, and doing so is efficient for several reasons. The main reason is that these Siheyuans, when residents start businesses (or continue to run their businesses) they are more likely to protect the structure of their own house than shop owners who rent Siheyuans. We can also look to the tourist attractions that have already adopted this method-Kyoto, for example, where the characteristics of most traditional buildings and shops are maintained. A special feature of these shops is that many of them are familyrun. Figures 10 and 11 show two buildings in Kyoto with a similar feature: the first floor serves as a shop, while the second floor serves as a residence. This helps maintain living patterns and architecture in Kyoto. However, another question arises: how to encourage the locals to run businesses if their shops might not have the ability to attract visitors and cannot survive in the market?

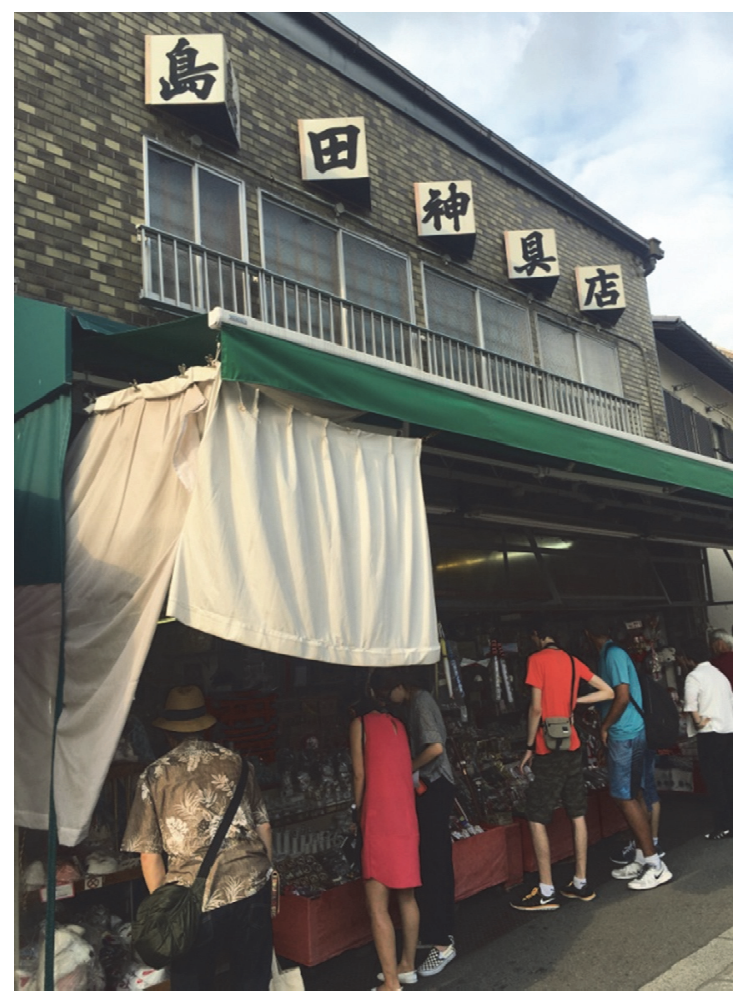

Figure 10. Religious shop in Kyoto

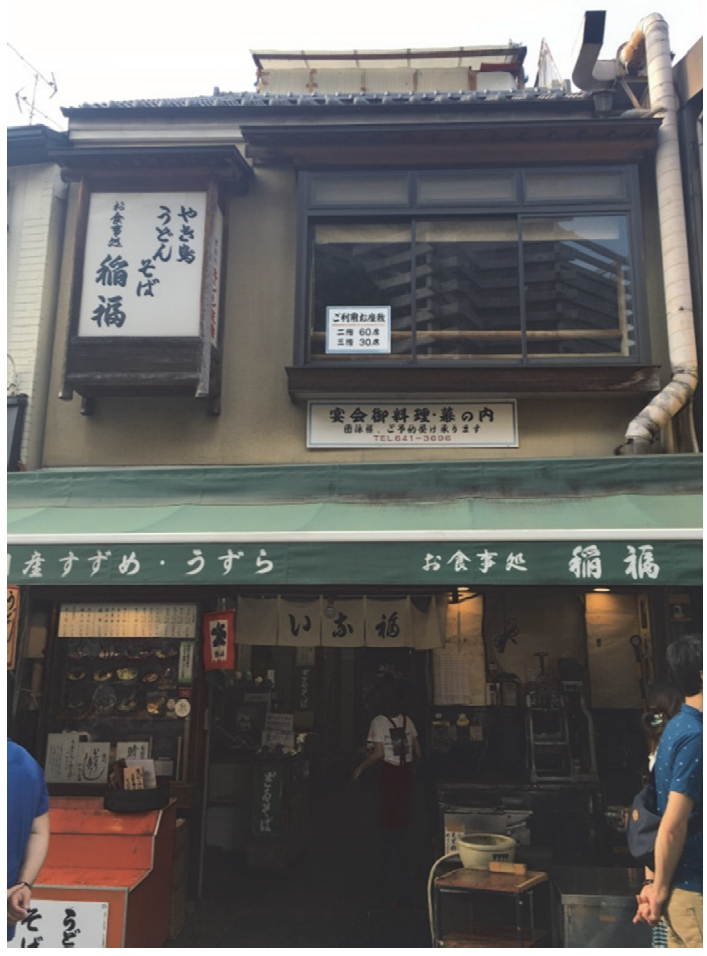

Figure 11. Restaurant in Kyoto

(photos by the author)

The most common elements in tourist attractions are shops and restaurants. In order to maintain the local culture of Hutongs, residents can open stores that sell traditional food and other products. However, simply running traditional shops and restaurants might not be enough to attract visitors. In Nanluoguxiang, there are few traditional restaurants and shops, perhaps because of the difficulty of surviving in the market. In contrast, there are many Lao Zihao (time-honored brands that sell products with local characteristics) in Dashilan, possible because that Dashilan was commercialized a long time ago. However, many of them (such as apparel stores) are facing difficult business operations because they cannot completely adapt to market changes, such as the change in consumer preference. To make traditional shops and restaurants capable of surviving in commercialized Hutongs, they should satisfy the market demand by actively adjusting their management patterns. It is crucial to maintain these stores' traditional culture and architectural characteristics. Running such shops and restaurants can involve storytelling, such as introducing the background and history of the products, shops, and founders to consumers. In an ideal scenario, these traditional shops are able to compete with other shops in Hutongs, allowing visitors to understand local culture and the uniqueness of these tourist spots.

Moreover, well-preserved houses can serve as museums that exhibit the history of these spaces and the ways that people have inhabited them for centuries. Although there are museums in some Hutongs, they do not currently exhibit much of the architectural or aspects of local life. Having such museums enables the locals to spread their culture and show the importance of preservation to the public.

Secondly, in order to maintain the basic form of historic buildings, the government needs to avoid demolishing or 
renovating them in ways that alter their spatial layout or architectural style. In addition, the government should set up more precise policies in respect of commercial tenants (such as to limit the types of shop that could cause damage to Siheyuans).

\section{Conclusion}

In summary, many Hutongs have been commercialized in recent years because of their architecture and potential for tourism. Local residents, shop owners, the government, and tourists have all played a role in the process of commercialization. However, if the government focuses too much on promoting tourism and the economy and neglects the importance of protecting the layout of Siheyuans and maintaining the Hutong-Siheyuan living pattern, the commercial value (and more importantly, the historical and cultural value) of Hutongs may decrease or disappear. As we can see in the Nanluoguxiang and Dashilan, inappropriate commercialization plans can be quite harmful to these historic sites in terms of preservation. A potentially more sustainable method to develop commercialized Hutongs is rather simple - to preserve much local culture and architecture. It is also necessary to encourage locals and traditional brands to establish stores in Hutongs. To make these traditional shops competitive, the shop owners need to actively adjust management modes while maintaining the local culture and techniques. Introducing restaurants and shops that are unrelated to the local culture can bring positive effects, but it is important to control the number of such commercial tenants.

The solutions presented in this paper need to be further developed in the future. Additional questions worth asking are whether or not Kyoto's commercial mode can be applied to Beijing's Hutongs, and whether locals there would be willing to start their own businesses.

Moreover, apart from shops and restaurants, it is necessary to develop cultural industry (such as, but not limited to, the museum mentioned in the previous section), since Hutongs represent an important part of Beijing - and, more broadly, Chinese - history and culture. If so, these Hutongs will not only attract tourists, but also local people to consume and to explore local culture. Just as Liang and Chen proposed in their report, these Hutongs would become small city museums and additionally raise public attention for preservation. They would not only serve as a place for amusement, but also as a spiritual home for all citizens in Beijing and other parts of China.

\section{Reference}

Beijing Dongcheng District Municipal Government. (2014). Measures for the Protection and Management of the Historical and Cultural Blocks in Dongcheng District. Dongcheng District Municipal Government Document No.56 [2014]. Retrieved from http://www.bjdch.gov.cn/n3952/n3970/n3974/c1039633/content.html

Beijing Municipal Government Office. (2002). Suggestions on the House Renovation Project. Beijing Municipal Government Office Document No.25 [2002]. Retrieved from http://www.chinalawedu.com/falvfagui/fg22598/134223.shtml

Beijing Municipal Government. (1999). Planning for the Preservation and Control Scope of Conservation Districts of Historic Sites in the Beijing Old City. Beijing Municipal Government Document No. 24 [1999]. Retrieved from http://zhengce.beijing.gov.cn/zfwj/25/26/421256/11571

Beijing Municipal Government. (2012). Guidance on the planning and construction of the city touristic function area and suggestions on developing Beijing tourist industry. Beijing Municipal Government Document No.25 [2012]. Retrieved from http://zhengce.beijing.gov.cn/zfwj/25/26/421256/12369

Hou, Ri. (2013). Historical Atlas of Beijing (2th ed.). Beijing: Beijing Publishing Group Wenjin Press.

Li, D., Wu X., \& Ren J. (2005). Planning and Rehabilitation of Conservation Districts of Historic Sites. Retrieved from http://zfxxgk.beijing.gov.cn/11011502/gzdt53j/2015-07/22/content_34484.shtml

Liang, S., \& Chen, Z. (1950). Suggestions on the Location of the Administrative center of the Central People's Government. Beijing.

Liu, B. (ed.). Beijing Hutong. (Beijing: China Travel and Tourism Press, 2008), 52.

MINISO (2018). MINISO. In Baidu Baike. Retrieved October 10, 2018, from https://baike.baidu.com/item/MINISO 名创优品/12622453? fr=aladdin.

Standing Committee of Beijing Municipal People's Congress. (2005). Regulations on the protection of Beijing historic and cultural sites. Standing Committee of Beijing Municipal People's Congress Article 32. Retrieved from

http://so.beijing.gov.cn/view?qt=\%E5\%8C $\% 97 \% \mathrm{E} 4 \% \mathrm{BA} \% \mathrm{AC} \% \mathrm{E} 5 \% 8 \mathrm{E} \% 86 \% \mathrm{E} 5 \% 8 \mathrm{~F} \% \mathrm{~B} 2 \% \mathrm{E} 6 \% 96 \% 87 \%$ Е5\%8C\%96\%Е5\%90\%8D\%E5\%9F\%8E\%E4\%BF\%9D\%E6\%8A\%A4\%E6\%9D\%A1\%E4\%BE\%8B\&loca 
tion $=2 \&$ reference $=$ dcq38059\&url=1BF35E1 A375D90B9BD2C8B2D41B3F945AB7776326E07326EE2F4 2D5BBEE19C9B9875C334CDBF0AB8C20DFE17DEABDCF015140895FE13D0039C75A234D2E37D17

DAECC4236E8BAE64EC6246FD1DD93987\&title=\%E5\%8C\%97\%E4\%BA\%AC\%E5\%8E \%86\%E5\%8F \%B2\%Е6\%96\%87\%Е5\%8C\%96\%E5\%90\%8D\%E5\%9F\%8E\%Е4\%BF\%9D\%E6\%8A\%A4\%E6\%9D\%A1 $\% \mathrm{E} 4 \% \mathrm{BE} \% 8 \mathrm{~B} \&$ database $=$ all

Wang, G. (2007). Government Work Report. Beijing Xuanwu District Municipal Government Document No.1 [2007].

\section{Notes}

Note 1. The opening and reform was also a cause of the Hutongs' commercialization because the government established the socialist market economy system under this policy with the shift from a planned economy to a market-based one. Numerous shops were allowed to be established and thus allowing a higher level of commercialization.

Note 2. Some residents consider Siheyuans inconvenient as few have independent bathrooms.

Note 3. For more, see the Beijing Municipal Tax Service, State Administration of Taxation.

Note 4. In 2014, General Secretary Xi Jinping proposed to reinforce the "core functions of the capital" including political, cultural, international exchange, and science and technology innovation centers. The non-capital functions refer to city mechanisms inconsistent with the four core functions. The reason for this measure is to remove shops and services that are considered to be affecting the four city functions. For example, traditional manufacturing industries and wholesale markets are considered to affect the city's function and many of them were forced to close down.

Note 5. Dashilan had been one of the Langfang Hutongs, Lanffangsitiao, and was named "Dashilan" during the Qing Dynasty.

\section{Copyrights}

Copyright for this article is retained by the author(s), with first publication rights granted to the journal.

This is an open-access article distributed under the terms and conditions of the Creative Commons Attribution license (http://creativecommons.org/licenses/by/4.0/). 